\title{
Powering jobs: the employment footprint of clean cooking solutions in Kenya
}

\author{
Chih-Jung Lee $^{1 *} \mathbb{D}$, Rebekah Shirley ${ }^{1,2}$, Maureen Otieno $^{2}$ and Hope Nyambura ${ }^{2}$
}

\begin{abstract}
Background: The delivery of clean cooking access to the 1.2 billion people who cook with charcoal, kerosene, and firewood may have a strong localized employment impact. With the challenge of a rapidly expanding youth population and growing job scarcity in sub-Saharan Africa, understanding the impact of clean cooking on employment as well as the skills gap is timely. However, there is little definitive data on clean cooking jobs. Recognizing this data gap, we sought to conduct a study focused specifically on employment from the clean cooking sectors in Kenya, covering liquefied petroleum gas (LPG), bioethanol, biogas, and electric cooking solutions. This study provides an initial baseline and early estimate of the clean cooking sector's direct formal and informal employment based on one year of company survey data, expert interviews, available literature, and local focus group discussion.
\end{abstract}

Results: In Kenya, the clean cooking sector is estimated to provide about 19,000 direct, formal jobs and potentially 15,000 to 35,000 direct, informal jobs in 2019. While the clean cooking sector provided many jobs, the level of compensation and retention is low. In the LPG and electric cooking sector, sales and distribution are the biggest part of the workforce, while for bioethanol and biogas, manufacturing and assembling is dominant. The majority of the clean cooking sector's direct, formal workforce is reported to be skilled. Management, finance and legal, and product development and research are the most difficult skills to recruit for. Women's participation is lower than $30 \%$ in the clean cooking sectors studied, and managerial positions have higher women's participation than non-managerial ones.

Conclusion: This research exercise establishes a baseline for understanding the employment impact of the clean cooking sectors. However, a massive data gap persists. Our study shows that while clean cooking sectors, especially $L P G$, are already providing tens of thousands of jobs, further studies are critically needed to map the employment impact of delivering universal clean cooking access.

Keywords: Clean cooking, Employment, LPG, Bioethanol, Biogas, Electric cooking

\section{Background}

\section{Background of the study}

Globally, 2.8 billion people do not have access to clean cooking and use fuel sources that produce health hazards [1]. Among the population without access, 30\% are in sub-Saharan Africa [1]. In Kenya, 36 million people still cook with charcoal, kerosene, and firewood, a large

\footnotetext{
*Correspondence: chih-jung.lee@hec.edu

1 Power for All, San Francisco, CA 94108, USA

Full list of author information is available at the end of the article
}

majority of whom live in rural areas [1, 2]. Failing to deliver clean cooking solutions for all not only compromises the health and economic benefits that could otherwise be captured, but also forgoes the opportunity to create jobs for women, youth, and rural populations.

Indeed, past studies have shown that the expansion of clean cooking solutions has a strong influence on rural employment. As compared to off-grid solar jobs, jobs in the improved cookstove sector have a higher potential of reaching the poor, as the sector requires a local and relatively lesser skilled workforce [3]. For instance, original author(s) and the source, provide a link to the Creative Commons licence, and indicate if changes were made. The images or other third party material in this article are included in the article's Creative Commons licence, unless indicated otherwise in a credit line to the material. If material is not included in the article's Creative Commons licence and your intended use is not permitted by statutory regulation or exceeds the permitted use, you will need to obtain permission directly from the copyright holder. To view a copy of this licence, visit http://creativecommons.org/licenses/by/4.0/. The Creative Commons Public Domain Dedication waiver (http://creativeco mmons.org/publicdomain/zero/1.0/) applies to the data made available in this article, unless otherwise stated in a credit line to the data. 
many clean cooking programs are focused on training local masons and metalsmiths for the manufacturing of improved biomass cookstoves [4]. In Kenya, where the rural population is $73 \%$ of the total population as of 2018 , delivering clean cooking access could thus have a strong localized employment impact [5].

There is also potentially a strong gender dimension. On average, women spend $58 \mathrm{~h}$ a week collecting fuel and cooking in Kenya [6]. Dirty fuels cause indoor air pollution and evidence shows the resulting health hazards primarily affect women and children. Access to clean cooking options may thus improve health and time availability for women. Moreover, when women are engaged in the clean cooking workforce, studies show they deliver higher performance, for instance, often reporting better sales results than men [7]. Therefore, with women being the main end-users, beneficiaries, and agents of change of clean cooking access, the exploration of clean cooking jobs and gender characteristics warrants greater attention.

With the challenge of a rapidly expanding youth population and growing job scarcity across the continent, the need to understand the potential impact of clean cooking on employment as well as the barriers and solutions for unlocking employment opportunities (such as closing any outstanding skills gaps in the workforce) is all the more imminent. Such understanding can provide important information for policy makers, recruiters, and training institutions. Policy makers, for instance, can better consider the job creation potential of various clean cooking technologies in designing policy to drive energy transition; while training providers can better tailor their offers to meet the skill needs of the sector. While there is a strong anecdotal link between clean cooking and jobs, and an important policy motivation to better understand the linkage, there is little definitive data on this subject, especially for countries in sub-Saharan Africa.

Recognizing this data gap, our team sought to conduct a study focused specifically on employment from the clean cooking energy sector in Kenya-as one of the continent's most mature markets for clean cooking technologies. Our study provides an initial baseline and early estimate of the clean cooking sectors' direct, formal and informal employment profile, based on one year of detailed local company survey data, expert interviews, available literature, and in-depth focus group discussion.

\section{Literature review}

Providing better and cleaner energy access solutions to rural population can be a job engine in low-energy-access countries [8]. Past clean cooking employment studies have mostly focused on biomass-based improved cookstoves and consist mainly of monitoring and evaluation
(M\&E) exercises from donor-funded programs [9]. Such studies are useful but may not represent the sector as a whole. These individual M\&E case studies, while illustrative, do not provide enough data to approximate an entire market impact. Furthermore, they do not provide much insight into employment trends or characteristics, which limits their ability to inform policy.

In terms of LPG for cooking, very little information exists on employment estimates in sub-Saharan Africa. In 2018, the Global LPG Partnership (GLPGP) estimated that by implementing the National LPG Master Plan, an estimated 18,000 jobs would be created over the course of 15 years serving 18 million Cameroonians [10]. The World Bank also estimated that about 10 to 20 man-days of work are created per TJ of LPG consumption [11]. Moreover, Nigeria Liquefied Petroleum Gas Association estimated in 2017 that a 50\% shift from kerosene to LPG can create one million jobs [12].

Dalberg estimated that a full transition towards bioethanol, serving 500,000 customers in Kenya, can create between 40,000 to 70,000 new jobs. A majority of these jobs are in sugarcane farming, with just over 1,000 jobs in bioethanol production, storage, bulk transportation and retail sales, and distribution [13].

The International Renewable Energy Agency estimated that globally, the biogas sector provided some 333,000 jobs in 2015, with more than two-thirds of the jobs in China and India, and less than 17,000 in sub-Saharan Africa [14]. The Africa Biogas Partnership Program reported 350 jobs in three countries between 2016-2017 (Kenya 115, Tanzania 126, Uganda 109), although not all jobs may provide full-time employment, plus part-time unskilled labor [15].

Thus, while the employment impact of clean cooking is widely reported anecdotally in the literature and the M\&E frameworks of funded programs, there are few coherent efforts that track employment trends systematically, and sector-wide studies remains limited. Our study is intended to reduce this information gap through a direct, comprehensive, bottom-up survey of companies working in the clean cooking sector. To our knowledge, this is the first that such a study has been conducted for Kenya.

\section{Methods}

In this section, we explain the research questions, describe our research scope, and detail our research methods.

\section{Research questions}

The key questions that are answered in this study include:

- What is the scale of employment that derives from the use of modern and clean cooking technologies 
in Kenya, in terms of the number of persons engaged in direct formal and informal employment over the course of 2019? (see definition in Sect. "Technology scope)

- What are the characteristics of this employment, in terms of job function breakdown, gender representation, youth engagement, skill level, permanency, and level of compensation?

- What are the stated skills demands and recruitment challenges of the clean cooking workforce?

- What are the implications for clean cooking sector practitioners to deliver universal access (SDG 7) while stimulating the growth of decent jobs (SDG 8)?

\section{Research scope}

Geographic scope

The study focuses on employment within the clean cooking sector in Kenya, as one of the most developed clean cooking markets in sub-Saharan Africa. It captures jobs from the in-country activities that are located in Kenya, and held by Kenyan nationals and foreign workers. It does not consider the upstream employment impact from segments of the value chain that take place outside of Kenya, such as raw material extraction or manufacturing, nor does it take into account labor resource sharing of multinational companies (Additional file 1).

\section{Employment type scope}

The study aims to assess the direct jobs that are within the clean cooking sector in Kenya, including formal employment and informal employment through engagement with companies. While there is evidence of job creation being stimulated by the productive use of clean cooking technologies, through income-generating activities such as social entrepreneurship from women's groups, productive use jobs are not part of this study scope. Neither do we estimate indirect or induced jobs, defined, respectively, as those that are created through backward linkages, and forward linkages, such as when workers in the clean cooking sector spend salaries on goods and services throughout the larger economy. Such analysis would require a longitudinal study that collects employment data over a longer time span and would require macroeconomic data not readily available for Kenya, and as such is beyond our current study scope. See the Appendix 1 for a complete list of definitions for formal, informal, indirect, induced, and productive use jobs.

\section{Technology scope}

Clean cooking technologies are defined as those cooking solutions with low particulate and carbon monoxide emissions levels (IWA ISO Tier 3-4 for the indoor emissions indicator) [11]. The IWA tiers for indoor emissions are consistent with the World Health Organization indoor air quality guidelines. For the purpose of the study, only those cooking solutions that are based on modern fuels and renewable energy are considered. This includes the LPG, biogas, bioethanol, and electric cooking sectors, from fuel supply to accompanying cooking equipment (e.g., cylinders, cookstoves, etc.). Improved biomass-based cookstoves and kerosene-based cooking solutions are not in the scope of our research.

\section{Value chain scope}

The value chain of the clean cooking sector comprises two major segments: (1) the value chain of fuel supply and distribution, and (2) the value chain of cooking equipment manufacturing and distribution in relation to a particular fuel or energy source. The study covers both components for each cooking technology in scope. Each clean cooking technology value chain is unique and oftentimes the stakeholders involved do not overlap between technology types. As such, our survey tool comprised different sections, each with particular questions for an individual cooking solution. In addition to the value chain of fuel and cooking equipment, there is a ripple effect of the sector's job creation potential through research, business incubation, demonstration labs, and other supporting organizations. While these organizations play a key role to the growth of the sector, their employment potential is not accounted for in the study. Below we describe the value chain for each cooking solution and explain the rationale for scope.

\section{Description of the clean cooking technology value chains and scope inclusion}

Among all the clean cooking sectors in scope, the LPG sector has the largest market in Kenya. In 2018, there were an estimated 3.7 million households in Kenya that use LPG for cooking (primary or secondary use), about $29.7 \%$ of the population, and $18.9 \%$ of the households used LPG as the primary cooking fuel, as compared to $13.3 \%$ in $2015-16$ [2]. Household consumption of LPG makes up around $88 \%$ of all end-use LPG consumption in Kenya [16]. In 2018, annual import was 269.9 kilotonnes, with $87.5 \%$ arriving by sea and $12.5 \%$ arriving by road from Tanzania [16].

The use of LPG is much more common in urban areas than rural. $54 \%$ and $18 \%$ of households use LPG for cooking in urban and rural areas, respectively [2]. Consumption level also differs: an average urban household consumes about $1.3 \mathrm{~kg}$ of LPG per week (or $5.2 \mathrm{~kg} /$ month), while a rural household uses about $0.9 \mathrm{~kg}$ (3.6 $\mathrm{kg} /$ month) [2]. As a result, $77 \%$ of the residential 
LPG cooking gas is consumed by urban households, despite that the majority of the Kenya population is in rural areas.

The LPG market in Kenya is competitive. According to industry experts, about $45 \%$ of the market share is taken by large LPG marketing companies ('LPG marketers'), including well-known brands such as Total Gas by Total Kenya, Supa Gas by National Oil, and K Gas by Kenol Kobil., among others. Another 55\% of the market share goes to a large group of smaller but impactful companies. The number of licenced and registered marketers has increased over time. In 2019, the Energy and Petroleum Regulatory Agency (EPRA) introduced new regulations, LN100/2019, that requires all LPG distributors to be licensed with authorized brands [17]. Previously, illegal refilling activity was dominant in Kenya and many distributors were refilling the cylinders that they did not own. The introduction of LN100/2019 has reduced these activities and improved the safety standards of the workers [17]. The Energy Dealers Association (EDA), a consortium of 32 local gas suppliers, works closely with their distributors to comply with the new regulation [18].

The study scope includes bulk import and export of LPG, bulk transportation, bulk storage and cylinder filling, cylinder manufacturing, wholesale of cylinders, distribution of cylinders, and retail sale of cylinders by exclusive retailers. In Kenya, EPRA provides the licensing framework for the entire LPG sector except for the retail dealers, which are often informal, and relatively small businesses. The study captures all formal segments of the value chain. Figure 1 shows the part of the value chain activities that are included in the scope. However, some parts of the value chain, especially in LPG importing, are dominated by a few large companies. We were not able to capture some of the largest players in the sample, such as African Gas \& Oil Limited (AGOL), which imports $77.2 \%$ of the LPG from Mombasa. Sampling is discussed in Sect. "Sample representation" [16].

Bioethanol is a much less established sector as compared to LPG. Less than $0.1 \%$ of households in Kenya use bioethanol for cooking [2]. According to experts, there are more than 10,000 bioethanol residential users served mainly by three bioethanol producers and a few sales and distribution companies. There are fewer than 20 formal players along its fuel value chain in Kenya, including: sugar companies that produce bioethanol as a by-product, wholesalers that buy and transport bioethanol in bulk, retail sales and marketing companies, and last-mile distributors. According to our literature review and expert interviews, most bioethanol fuel for cooking is produced domestically, with imports from Tanzania and Uganda. However, because the current domestic production capacity is not keeping up with consumption growth, the sector expects to start importing fuel soon.

The survey included all formal segments of the bioethanol value chain, from cooking fuel production, which does not include bioethanol for non-cooking purposes, wholesale, to retail sales and distribution. In the case of the bioethanol sector, last-mile distributors are often self-employed local sales agents not directly employed by bioethanol companies, but rather, earning additional

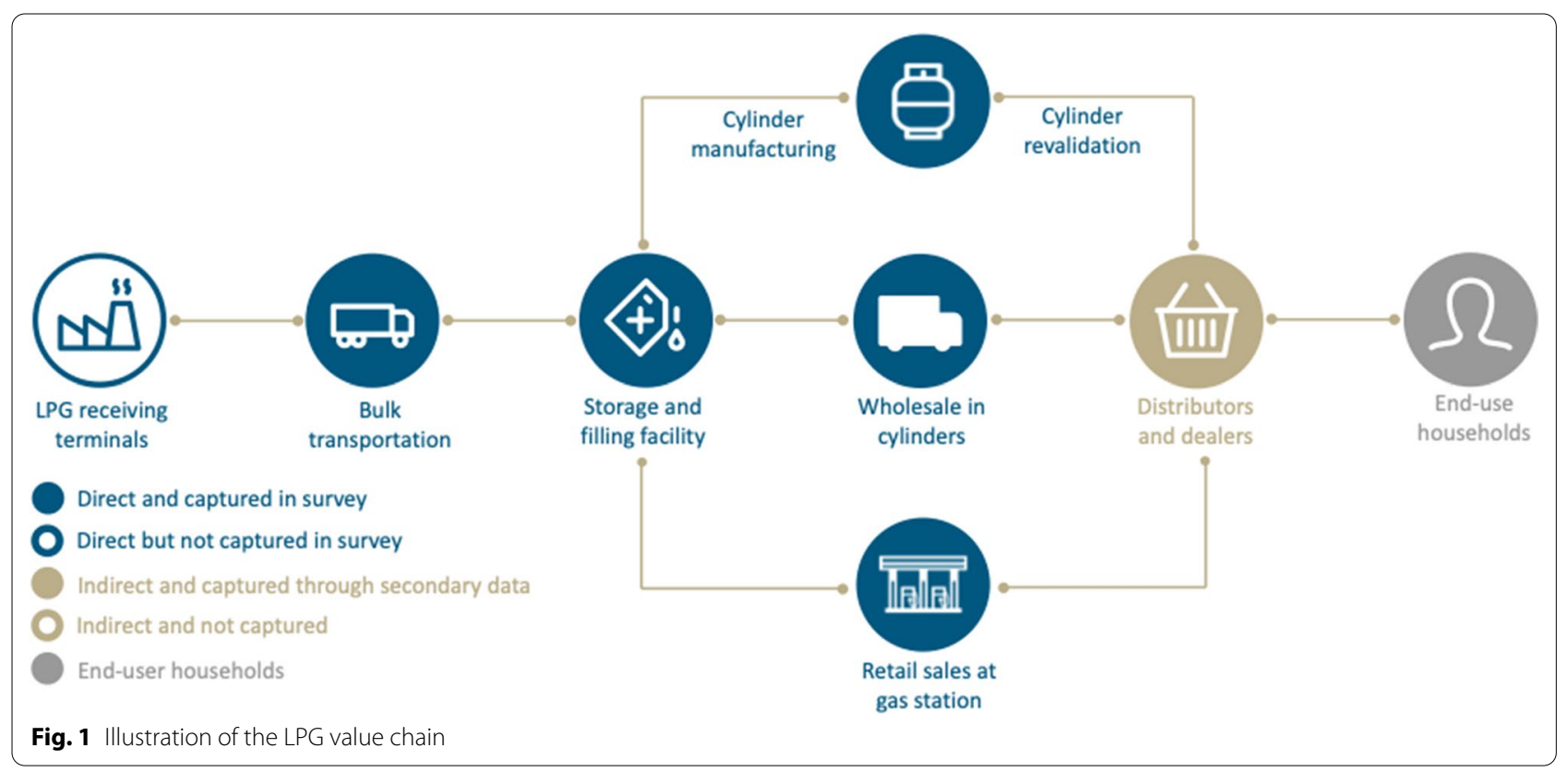




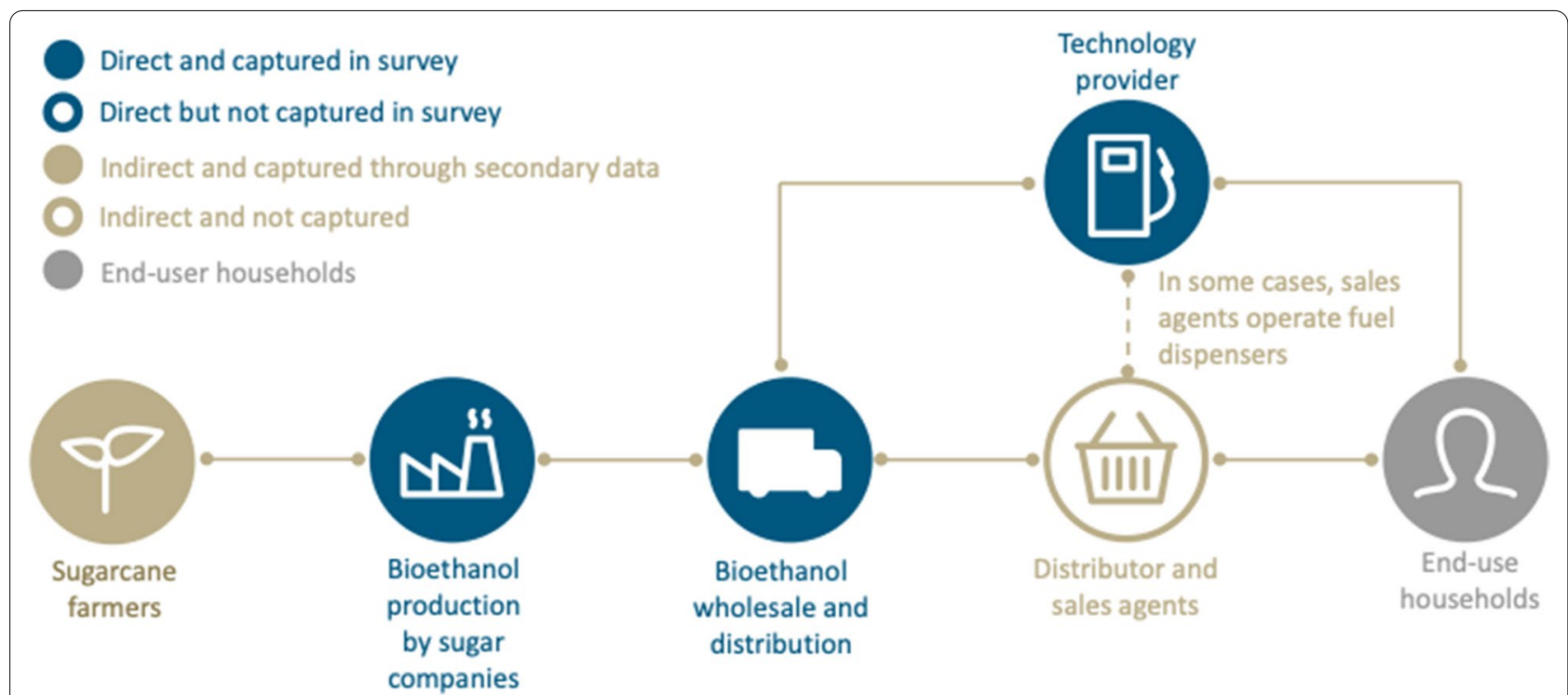

Fig. 2 Illustration of the bioethanol value chain

commission-based revenues. As such, we do not survey this informal segment of distributors directly, and it is intended as future work. Figure 2 illustrates the bioethanol value chain and identifies the part of the value chain activities that are captured in the study scope.

Biogas is an emerging clean cooking solution in Kenya, representing roughly $0.1 \%$ of the residential cooking solutions [2]. At the time of writing, there are about 21,000 biogas digesters in operation, serving not only household cooking needs but also productive use activities on the farms, according to Kenya Biogas Program. The primary end-users of cooking biogas are primarily located in rural areas where access to other energy sources is scarce and access to crop residue or animal waste is abundant. The biogas digester companies included in this study use floating drum, tubular biogas digesters and fixed-dome biogas digesters for homes or businesses who themselves become the primary operators.

Biogas companies operate along a very different supply chain, where the fuel and cooking technology are integrated. There are less than 10 companies that import or manufacture prefabricated systems, and 147 Biogas Construction Entrepreneurs (BCE) who not only construct fix-dome biogas digesters but also work with a wide range of biogas technologies, according to BioNet, an association of the BCEs. These biogas companies import, fabricate, assemble and install the biogas digesters, and they often provide training for operations and maintenance $(O \& M)$ and/or extension services to end consumers. Once the biogas digesters reach the operator, they are often used with mixed purposes: cooking, heating, lighting, and power generation [14].

Figure 3 shows the scope of the biogas value chain that the study covers, including domestic manufacturing and assembling, installation, construction, sales and after-sale services. The survey includes biogas companies from the formal sector and through expert focus group discussions, we have gained an understanding of the scale of employment impact stimulated through rural entrepreneurs owning and operating biogas digesters.

Electric cooking is a newly emerging cooking solution in Kenya. About 3\% of the households own an electric cooking appliance such as a mixed LPG-electricity stove, electric oven, electric coil stove or microwave [2]. These appliances, however, are most commonly used by high-end consumers in urban areas. For rural consumers, adopting clean cooking technologies for the first time, electric cooking is mostly used for fuel stacking alongside other fuel types.

In Kenya, the electric pressure cooker (EPC) is the most commonly promoted electric cooking technology and is perceived to be viable for rural weak-grid and offgrid areas due to its high efficiency to cook energy-intensive foods. While it is still an emerging technology, EPC has been proven to save significant costs when to displace charcoal and kerosene. Currently, EPCs are largely imported, with little local assembly or manufacture. As such, this study focuses on jobs from EPC import, sale and distribution, as shown in Fig. 4. It does not include the indirect jobs associated with electricity service provision in the utility sector. 


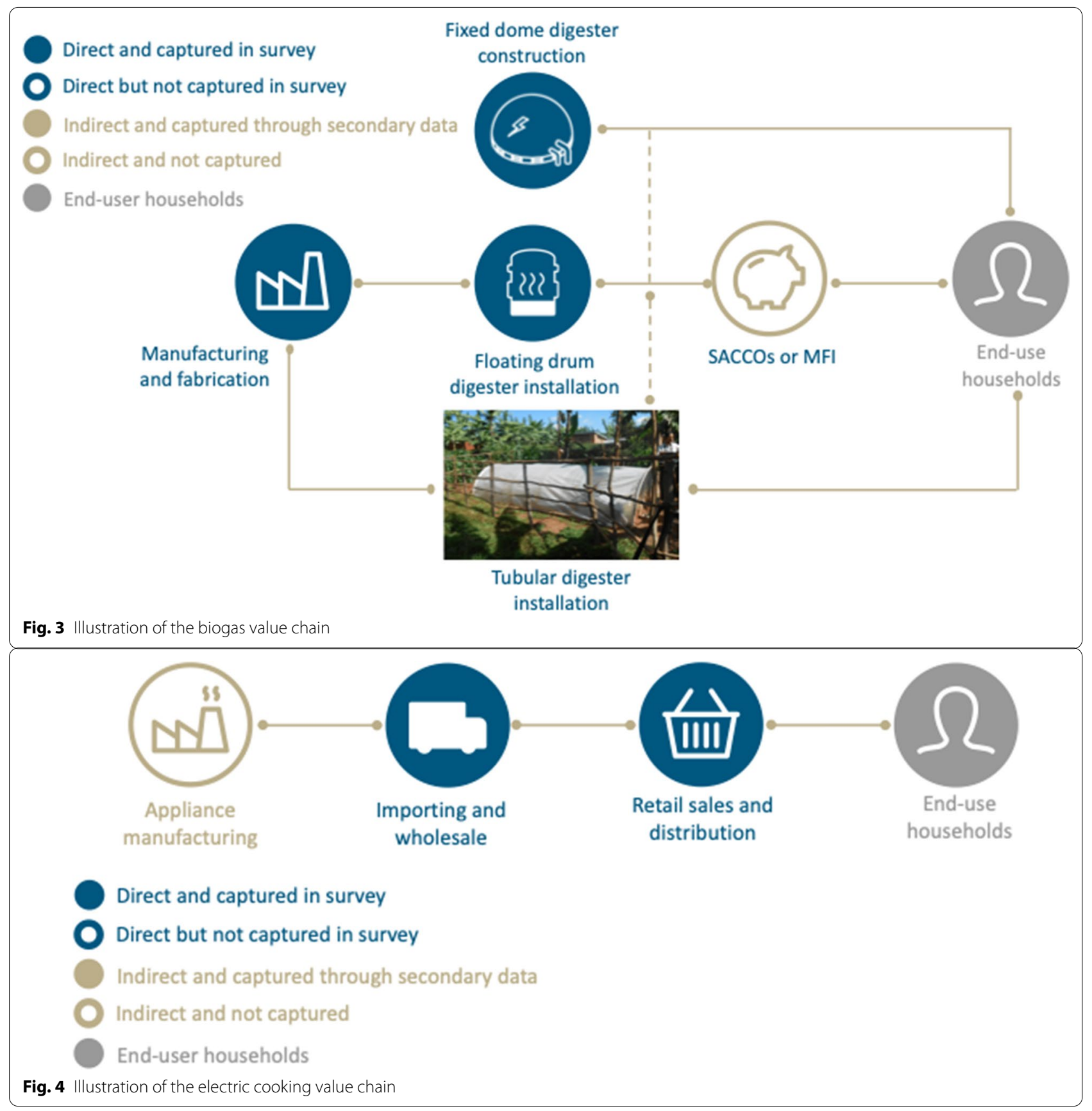

\section{Data collection and analysis}

Data collection was conducted through an online survey directed at companies in the clean cooking sector, complemented by data evidence collected through literature review, and interviews with industry associations and experts. Management and human resource officers were the main respondents to the survey.

The survey tool not only solicited direct, formal, and informal employment estimates from companies for the course of one year, but also asked questions related to the demographic trends of the respective company's workforce. The complete survey tool is provided in the Supplementary Material of this article. Data insights from these collection exercises were validated through focus group discussion with recognized local industry experts.

The data collection exercises proceeded as follows:

1. A contact list of clean cooking companies was developed with the support of the Powering Jobs cam- 
paign partners. The contact list covers the defined clean cooking value chain.

2. Survey was designed with input from these stakeholders and tested with a small number of commercial companies in Kenya to ensure appropriateness.

3. Survey was disseminated over the first quarter 2020. Targeted communications were sent to companies with large market share during data collection, particularly for the LPG sector, which is dominated by large market players.

4. After the survey was completed, our team visited and interviewed key companies that each represent more than $10 \%$ market share of their respective sectors.

5. To help contextualize survey findings, the team also conducted structured interviews with industry associations, NGOs, and regulatory authorities who provided insights on employment from their respective
Having translated reported direct formal jobs into FTE, we developed employment factors of the direct formal and informal jobs in 2019 by applying the following formulae:

$$
\begin{aligned}
& \text { Direct formal employment factor } \\
& \quad=\frac{\text { total number of direct formal jobs }}{\text { total reported volume of sales or processing capacity }},
\end{aligned}
$$

Direct informal employment factor

$$
=\frac{\text { Total numberof direct informal jobs }}{\text { Total reported volume of sales or processing capacity }} \text {. }
$$

Each part of the value chain has an employment factor that is then applied to a market estimate to map the employment impact to a sectoral scale. The formulae used in this method is as follows:

Total direct formal jobs $=$ direct formal employment factor $\times 2019$ market estimate,

Total direct informal jobs $=$ direct informal empoyment factor $\times 2019$ market estimate.

sectors. In-person interviews were held with Kenya Biogas Program (KBP), GLPGP, BioNet and Energy Dealers Association, and the Energy and Petroleum Regulatory Authority.

6. A focus group discussion was held with industry experts to validate findings and provide qualitative context for results and insights.

Calculation of full-time equivalence (FTE) of jobs reported in the survey and the interviews was computed using the following formulae to equate part-time and contract work with the workload of a full-time job:

FTE for a part - time job $=\frac{\text { part }- \text { time working hours }}{\text { full }- \text { time working hours }}$,

FTE for a contract job $=\frac{\text { average length of contract }}{\text { full }- \text { time retention }}$.

All direct, formal jobs presented in this report are in FTE terms. Therefore, while a company might employ many casual workers by giving out short contracts, its FTE direct, formal employment impact might be discounted due to the short duration of contracts. Informal jobs are not translated into FTE. While it is widely recognized that informal jobs are less secure and less compensated, the study has limited understanding of the quality of these jobs.
This methodology of mapping employment data to an employment factor (sometimes referred to as a job multiplier) is commonly used in past studies on energy and jobs. For instance, the method was originally used to estimate the employment impact of green investment programs. Kammen et al. and Wei et al., respectively, have estimated the employment impact of renewable energy, low-carbon energy, and energy efficiency using employment factors (such as jobs created per MW over the lifetime of an energy facility) $[19,20]$. Others have used an input-output (I-O) method, introduced by Leontief [21], that can estimate the employment impact on both direct and indirect jobs. This method is also recommended by the International Labour Organization (ILO) for estimating bioenergy jobs, especially when considering the interlinked relationships between the various production and consumption sectors [22]. This requires strong data on economy-wide linkages (often found in IO tables), not often available for sub-Saharan African countries. A further challenge to employment studies in Kenya is the availability of primary data specific to the energy access context. For example, an employment factor derived for a large-scale biogas plant, for instance, is not applicable to a small-scale plant of less than $15 \mathrm{~m}^{3}$ in size. Our study relies on data directly from companies through survey and interviews to develop employment factors, and as such, lays a foundation for further work. 


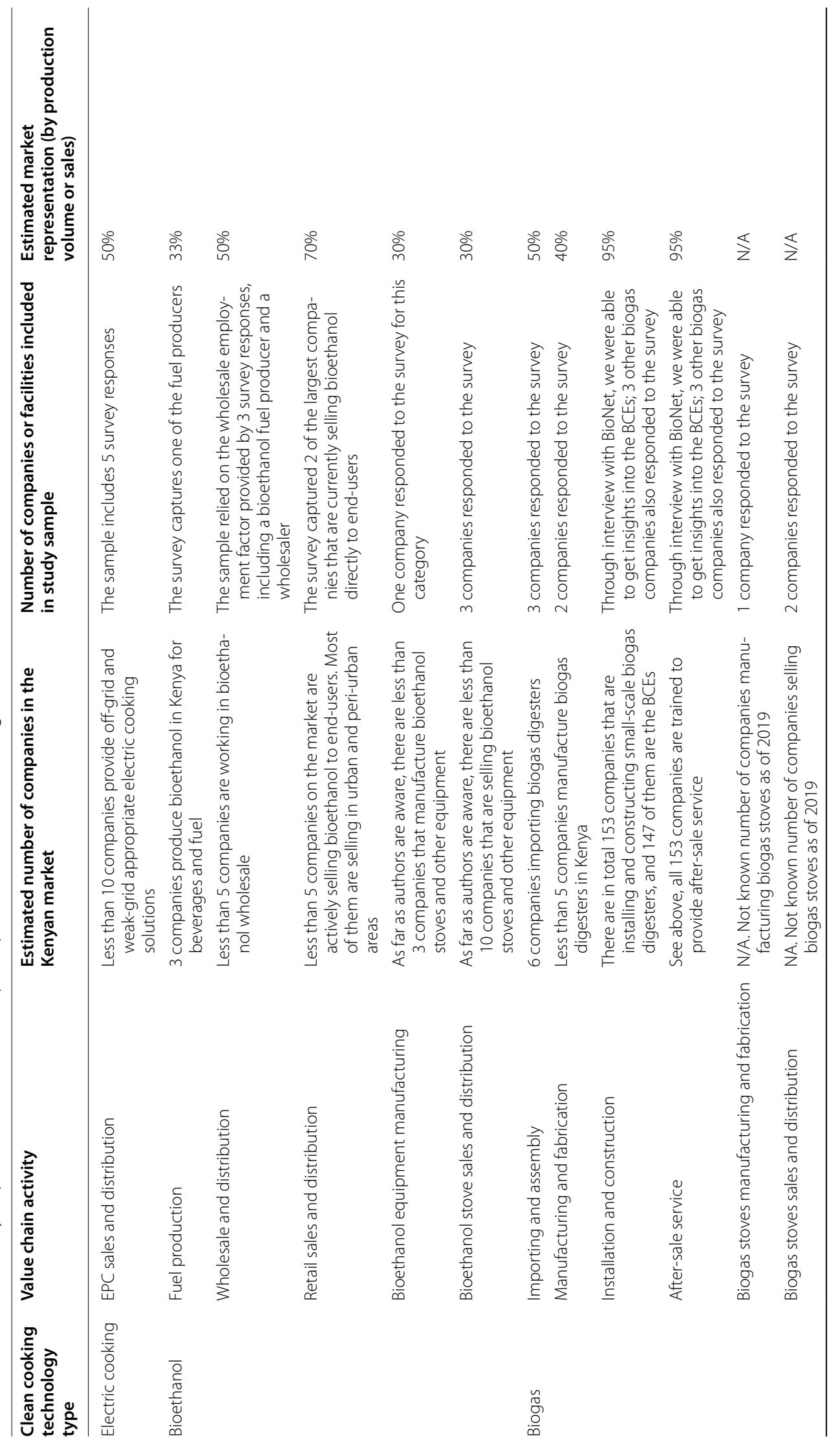




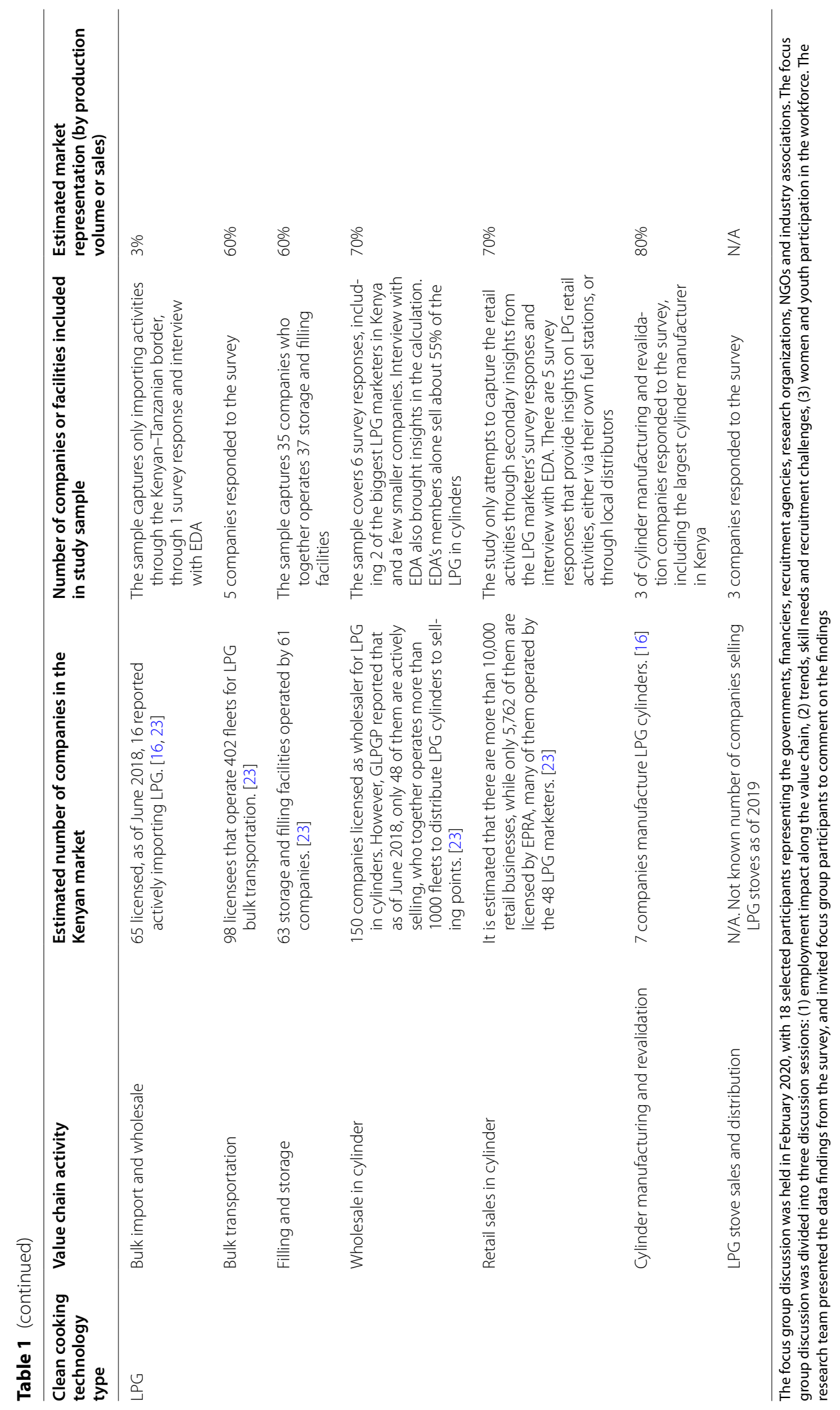




\section{Sample representation}

In total, there were 31 survey responses and 13 organizations interviewed. The survey respondents and interview participants of the study represent a significant share of the market for most parts of the value chain segments. Table 1 summarizes the population, sample of the study, market representation of the employment factors, and margins of error for each part of the value chain activities in each sector.

The study reports margins of error at a $90 \%$ confidence level. In the findings, the study provides both conservative estimates and high employment estimates, to demonstrate the range of potential employment from the deployment of clean cooking solutions. The high employment estimates were based on all the employment factors collected, regardless of the market representation and margins of error. The conservative employment estimates were based on only the part of the value chain where the employment factors' margins of error are lower than $15 \%$. As shown in Table 1, we were not able to collect sufficient data in some parts of the value chain such as LPG bulk import, LPG stove sales and distribution, biogas stove manufacturing, and biogas stove sales and distribution, and therefore, the employment impacts of these parts of the value chain are not considered in the conservative estimates.

\section{Results}

\section{Clean cooking employment estimates}

According to our survey findings, the total number of persons directly employed by the clean cooking sectors in Kenya in 2019 was about 11,000-19,000 FTE, of which, 9,100-17,000 are in the LPG sector, 700 in the bioethanol sector, 800 in the biogas sector, and 200 in the electric cooking sector.

We estimate that in 2019, the total number of persons employed informally the clean cooking sectors in Kenya was between 15,000 and 35,000. The large majority are in the LPG sector, 800 in the biogas sector, and 900 in the bioethanol sector. There is potentially much wider informal job employment from the LPG sector, especially in its end-use sales and distribution activities.

The latest available estimate shows that the charcoal sector employed nearly 900,000 persons for production and trade, and contributed US\$ 1.6 billion per year to Kenyan economy in 2013 [4]. Assuming that the size of the charcoal workforce remained the same, by 2018 , the sector was serving about 4.9 million households who used charcoal for cooking [2]. This means that roughly 180 people are employed to serve every 1000 households. This is significantly higher than the employment factor of the LPG sector from this study, which is 7 jobs per 1000 households. The finding shows that the employment potential of charcoal is more than 20 times that of the LPG sector and as a result, the job displacement effect of fuel switch from charcoal to LPG may be strong. On the other hand, the employment factor estimated for the biogas sector is about 263 jobs per 1000 households, much higher than the charcoal sector.

This survey also asked companies to report the likelihood of their respective clean cooking solutions being used for biomass displacement or fuel stacking. Figure 5 shows that bioethanol and biogas are far more likely to displace biomass cooking than LPG and electric cooking. Moreover, results find electric cooking is almost always used for fuel stacking. As illustrated from the data, it is

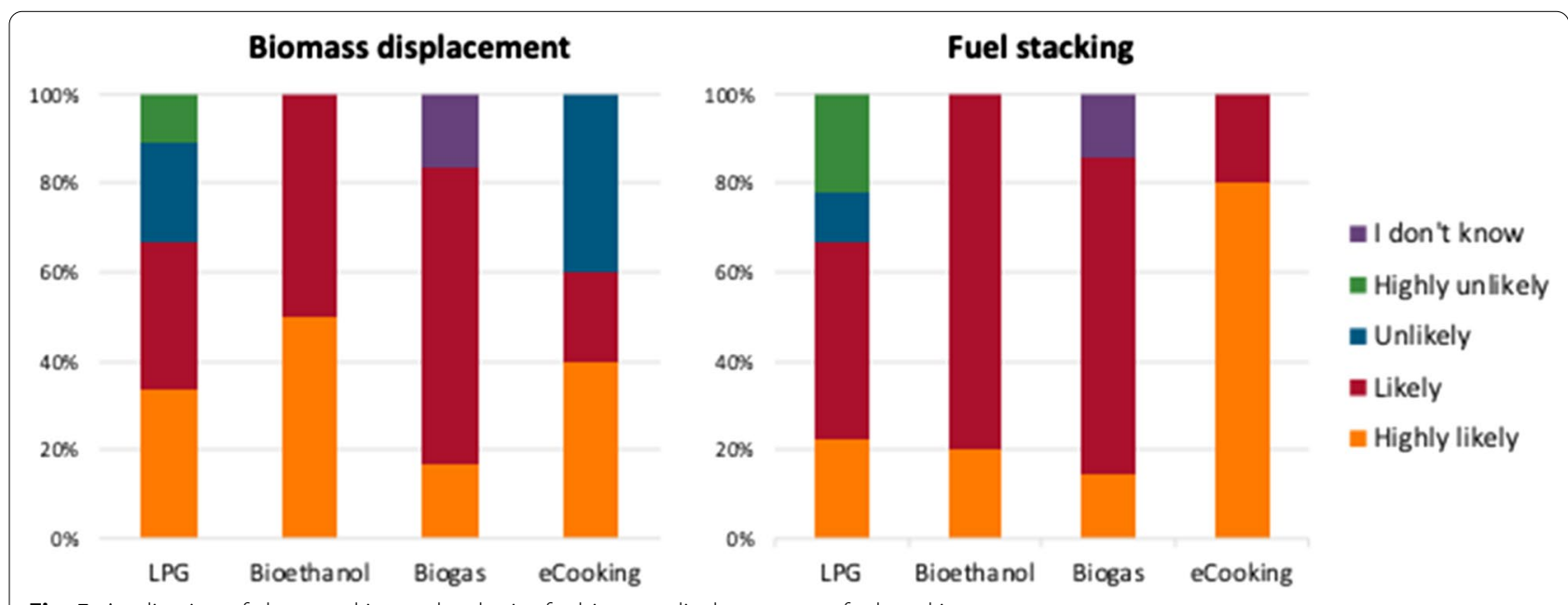

Fig. 5 Application of clean cooking technologies for biomass displacement or fuel stacking 
difficult to distinguish purely new clean cooking access, as opposed to stacking, and attribute jobs thereto.

While a useful point of departure, charcoal workforce data and our clean cooking employment estimates cannot be directly compared, as further considerations would include displacement effect, the formal and informal nature of the employment, differences in retention, and level of compensation, etc.

\section{Employment in the LPG sector}

In the LPG sector, job estimates broken down by function were as follows: import and bulk wholesale accounted for 3400 direct formal jobs, transportation in bulk about 400 jobs, storage and filling about 1000 jobs, wholesale in cylinder 3100 jobs, and retail sales in cylinder 3800 jobs. The sector also provided job estimates along its cylinder value chain: cylinder manufacturing plants provided 300 jobs and revalidation provided 200 jobs. In addition, there were 4500 jobs in the LPG stove value chain. Figure 6 shows that in 2019, the LPG sector provided about 17,000 direct formal jobs and 9100 direct formal jobs if LPG bulk import and stove sales and distribution jobs are not considered.

Direct informal job estimates in the formal sector was 300, marginal compared to direct formal jobs. These informal jobs are often casual laborers who work as loaders in depots and filling plants. While they are characterized by some companies as informal labor, these workers more often get short contracts of a few months but renew their contracts regularly.

The LPG sector not only creates a large number of jobs along its formal value chain, it potentially has a wider impact in its downstream linkages among retailers, distributors and selling points of LPG in cylinders. In addition to the 3800 direct formal jobs provided by some of the LPG marketers who also engage in direct retail sales to end-users, early estimates of the downstream retail job impact falls between 10,000 and 35,000 , provided by 10,000 to 18,000 retailers according to the analysis and EDA feedback. Each retailer would employ roughly one marketing person and one delivery person, distributing to one to five selling points that further serve about 50 to 100 households in urban areas and 20 to 30 in rural areas. The influence of employment impact of these selling points, is however less obvious, as most selling points are already existing businesses such as supermarkets and small kiosks. According to experts, selling LPG in cylinders often does not create new jobs in these selling points, but instead brings in new revenue for the business.

About $40 \%$ of the 10,000 to 35,000 retailer jobs at the moment are formal. The other $60 \%$ of the jobs have unknown status. The latest regulation LN100/2019 dictates that all LPG retailers should be licensed by EPRA and it is regulated that LPG retailers can only sell the brands that they are licensed for [17]. From September 2019 until the time of writing, 5672 LPG retailers have registered their businesses and obtained licenses from EPRA [23]. Employment of these retailers are therefore more formalized. The remaining LPG retail businesses are given until the end of the first quarter of 2020 to register and obtain license for their businesses. However, according to experts this may have a negative short-term impact on employment, due to the costs associated with licensing (estimated to be at least US\$50) [17]. Some retailers may choose to give up on the LPG business, and therefore, leading to short-term job loss. On the other hand, long-term positive impact of the Act expects continuous job growth and improved health and safety of LPG jobs due to better work environment, higher quality standards, and reduced conflict between legitimate brand owners and illegal refillers.

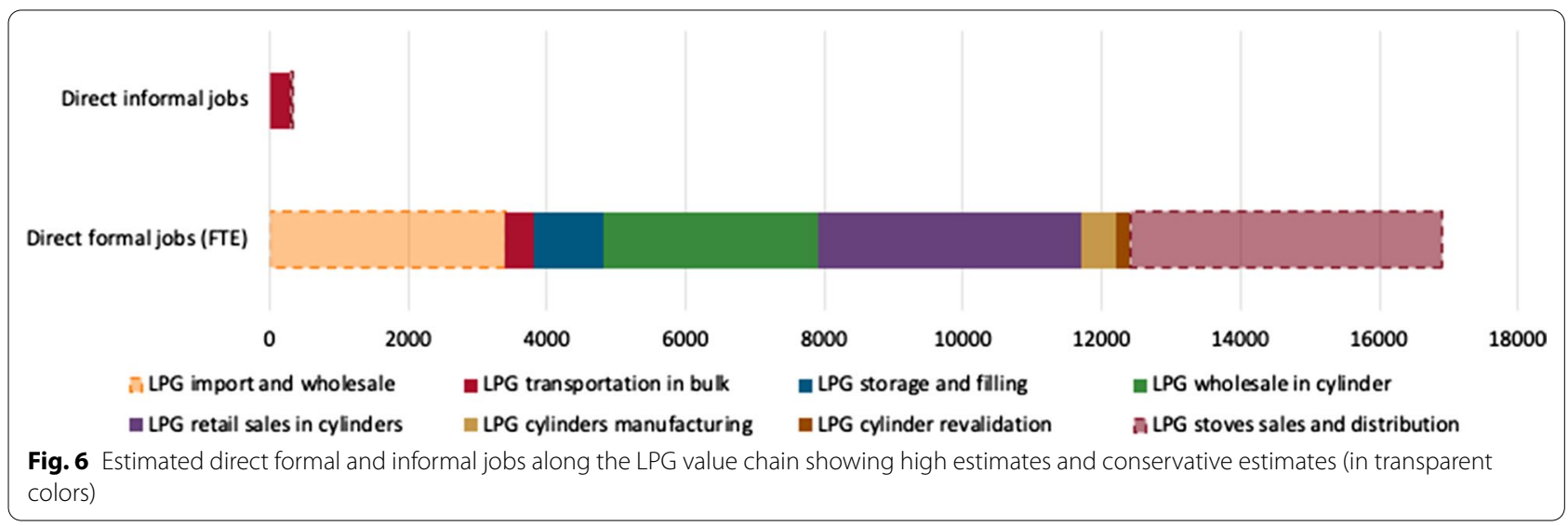




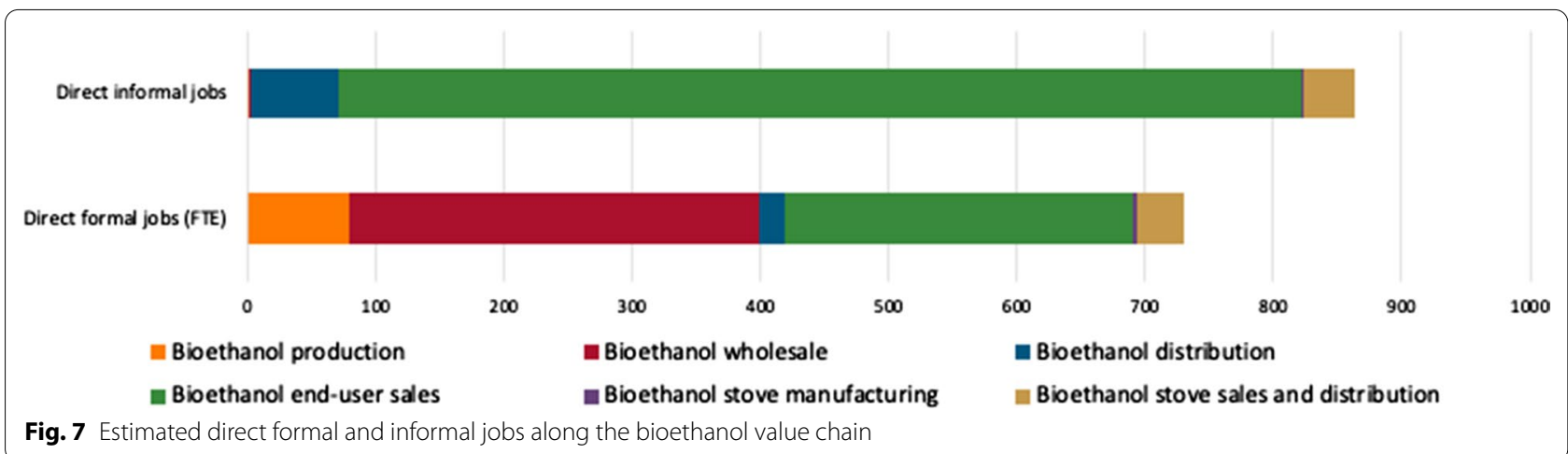

\section{Employment in the bioethanol sector}

In the bioethanol sector, production of bioethanol cooking fuel provided about 80 direct, formal jobs, wholesale and distribution provided 340 jobs, and retail sales and distribution provided 270 jobs, and bioethanol equipment manufacturing, sales and distribution provided 40 jobs. Figure 7 shows the estimated direct formal and informal employment impact along the bioethanol value chain in 2019.

Bioethanol fuel is produced in Kenya as a by-product of sugar production. About $85 \%$ of the bioethanol produced in Kenya is sold to the beverage companies, while the remaining $15 \%$ is used as fuel, according to experts. After discounting for the percentage used as fuel, we estimate the sugar companies themselves provided 80 direct formal jobs for bioethanol cooking fuel production, while wholesale activities account for 320 direct formal jobs.

Further upstream linkages in sugarcane farming may also experience indirect employment impact. Approximately 50,000 sugarcane farmers may benefit from the additional value-add to their production activities due to the use of bioethanol as cooking fuel [24]. However, the data input from the literature has not been recently updated and the assumption of the number of sugarcane farmers in Kenya was published in 2011. Therefore, the study has low confidence in the potential impact of bioethanol production on upstream sugarcane farmers' income. Furthermore, there is no evidence of additional job creation in sugarcane farming from bioethanol.

Our findings roughly fall in the range of Dalberg's early projection in 2018, when the bioethanol sector was just emerging. It was estimated that to serve 500,000 customers, the bioethanol sector would create 40,000 to 70,000 new jobs, mostly in sugarcane farming, with slightly over thousand jobs in the other parts of the value chain [13].

About 800 informal jobs were in the sales and distribution activities of bioethanol fuel value chain and 40 in stoves sales and distribution. These informal jobs are mainly sales agents, kiosk business owners who sell bioethanol alongside their regular businesses. As a result, the influence of these informal jobs is unknown.

\section{Employment in the biogas sector}

The biogas sector provided about 5 direct formal jobs in importing, 450 jobs in manufacturing and fabrication, 220 jobs in installation and construction, 320 jobs in after-sales services, and 30 jobs in its stoves value chain.

In addition to direct formal jobs, the sector also provided about 750 informal jobs in installation and construction, and another 50 in after-sales services. Figure 8 shows that the LPG sector provided about 1000 direct formal jobs in 2019, and 970 direct formal jobs if those from stove sales and distribution are not considered.

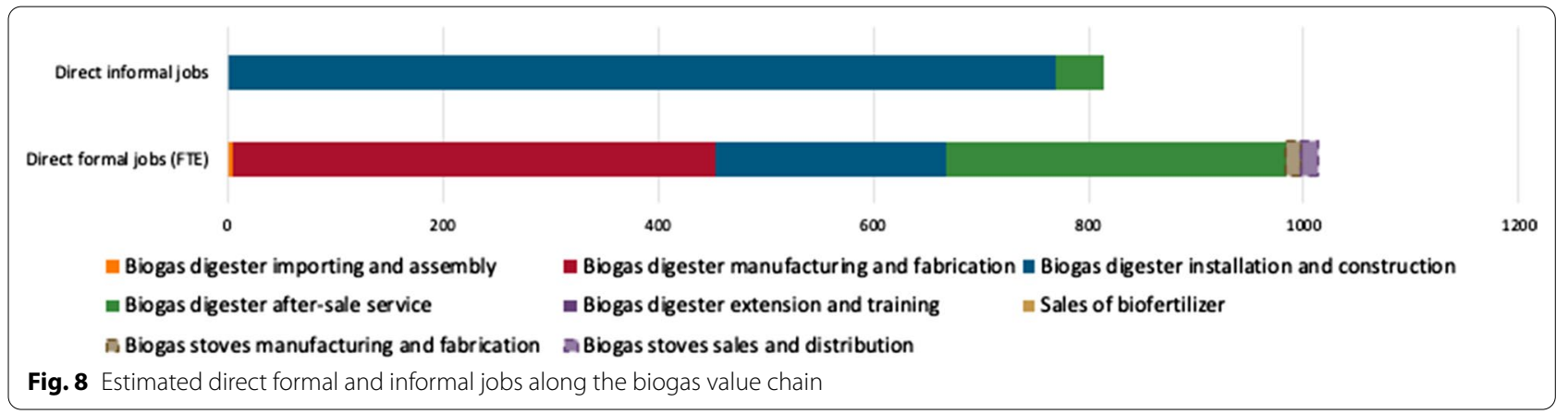


There are a few biogas technology providers that import, assemble and fabricate the biogas digesters. Most of these companies are small, and their employees work across different functions. Therefore, it is not expected that only 5 FTE jobs are provided to import biogas digesters. These moveable systems generally take less than a day to assemble. Usually, a salesperson and a technician are called on site to carry out the installation after a customer has placed an order. The technician may go back to service the system after 3 months.

Alongside the biogas technology providers, about $60 \%$ of the market share is taken up by the BCEs who construct fixed-dome biogas digesters locally. A BCE generally has at least one full-time entrepreneur who is equipped with the technical knowledge and business training. The entrepreneur would rely on the support of about 5 to 6 local masons. When a customer places an order, the BCE can construct a fixed-dome, domestic system within two weeks, with the support of one mason and three unskilled casual workers.

In Kenya, there are 147 BCEs, all of which are formally registered as businesses. These BCEs play a crucial role in the success of the biogas sector because they are in close and direct contact with the end users. In addition to their usual fix-dome system construction work, the BCEs sometimes source from the biogas technology providers. The high potential of employment impact of the biogas sector can also be observed in the growth of BCEs. Every one or two years, the masons who used to work for a $\mathrm{BCE}$ would branch out and start businesses of their own as soon as they learn the trade.

Although productive use jobs are out of the study scope, the biogas sector, in particular, has very high potential to be creating income-generating opportunities, according to the experts in the focus group discussion. In addition to generating biogas for cooking, the bio-slurry output of a biogas digester can also be a great source of biofertilizer. In some cases, about $10 \%$ to $20 \%$ of the biogas digesters are used for power generation, brooding or egg incubation. However, the extent to which these activities can create jobs is difficult to estimate.

\section{Employment in the electric cooking sector}

Electric cooking is an emerging clean cooking solution in Kenya. General perception of the technology is that it currently caters to higher income consumers. There are a number of solutions that are now designed to be compatible with mini-grid or weak-grid rural contexts so this is likely to change in the future. EPC, for one, have been proven to be a more efficient and cost-effective way to cook certain types of food.

In 2019, the importing, wholesale, retail sales and distribution activities of EPC provide about 200 direct formal jobs. See Fig. 9 for more details on jobs breakdown along the value chain. Currently, there is no manufacturing activity of EPC in Kenya. While the electric cooking market is still nascent in Kenya, Kenya Power (KPLC) has formed key partnerships to raise awareness and pilot electric cooking initiatives in rural areas. There are already players on the market that are exploring the possibility of manufacturing of EPC as domestic demand picks up.

\section{Clean cooking employment trends}

In this section, we discuss the employment trends within the clean cooking sectors studied, including skill level, compensation level, retention, and women and youth participation. All findings describe the direct formal workforce only, unless specified otherwise.

\section{Skill level and retention}

The direct formal jobs in the clean cooking sector are highly skilled. In the LPG and electric cooking sectors, more than $80 \%$ are skilled jobs. The biogas sector, on the other hand, reported a lower percentage of skilled labor. This, however, does not imply that most jobs in the biogas sectors are unskilled. In the biogas sector, the most indemand skills are more often semi-skilled masons, who are equipped with the technical knowledge but do not necessarily possess higher education.

In terms of the informal jobs, the LPG sector's informal workers are rarely skilled. These workers are mostly the loaders who are working at depots or filling plants. The work undertaken by the loaders is labor-intensive and requires little skill and training.

Direct formal jobs (FTE) 
While LPG and electric cooking sectors are the most skilled sectors, both sectors report short employee retention. On average, employees stay 18 months in the LPG sector, 24 months in the bioethanol sector, 36 months in the biogas sector and 20 months in the electric cooking sector. This is lower than the decentralized renewable energy sector in Kenya, where employees generally stay for more than 30 months [25]. See Fig. 10 for comparison of skill level across different sectors.

\section{Level of compensation}

According to the survey findings, shown in in Fig. 11, the level of compensation is highest in the LPG and electric cooking sectors. Both sectors pay more than $80 \%$ of their managerial employees more than US\$ 500 per month, as compared to just over $40 \%$ in the bioethanol sector and barely $20 \%$ in the biogas sector. For non-managerial employees, more than $80 \%$ of the workers earn more than US\$ 200 per month in the LPG and electric cooking sectors, while it is only $50 \%$ in bioethanol and $20 \%$ in the biogas sector. All informal workers in the bioethanol and biogas sectors are estimated to earn less than US\$200 per month.
The clean cooking sector's level of compensation can be compared to the charcoal sector. With the exclusion of the biogas sector, charcoal producers in Kenya earn about US\$ 60 per month [11], this is well below the reported monthly earnings range of direct formal jobs in the clean cooking sector. This insight validates the earlier assertion that the displacement effect of fuel switching is a complex topic. While the total number of jobs may decrease due to better labor efficiency in the clean cooking sectors, the level of compensation is likely to improve.

\section{Women and youth participation}

The survey response data (in Fig. 12) showed that in the clean cooking sectors, women's participation is higher in managerial positions than non-managerial positions; it is also higher in the bioethanol and electric cooking sectors, as compared to the LPG and biogas sectors. This can be explained by the fact that many direct formal, nonmanagerial jobs in the sector are labor-intensive. Take the LPG sector for example: in a storage and filling plant, it is mostly men who are operating the machinery and loading the cylinders. For the biogas sector, most non-managerial

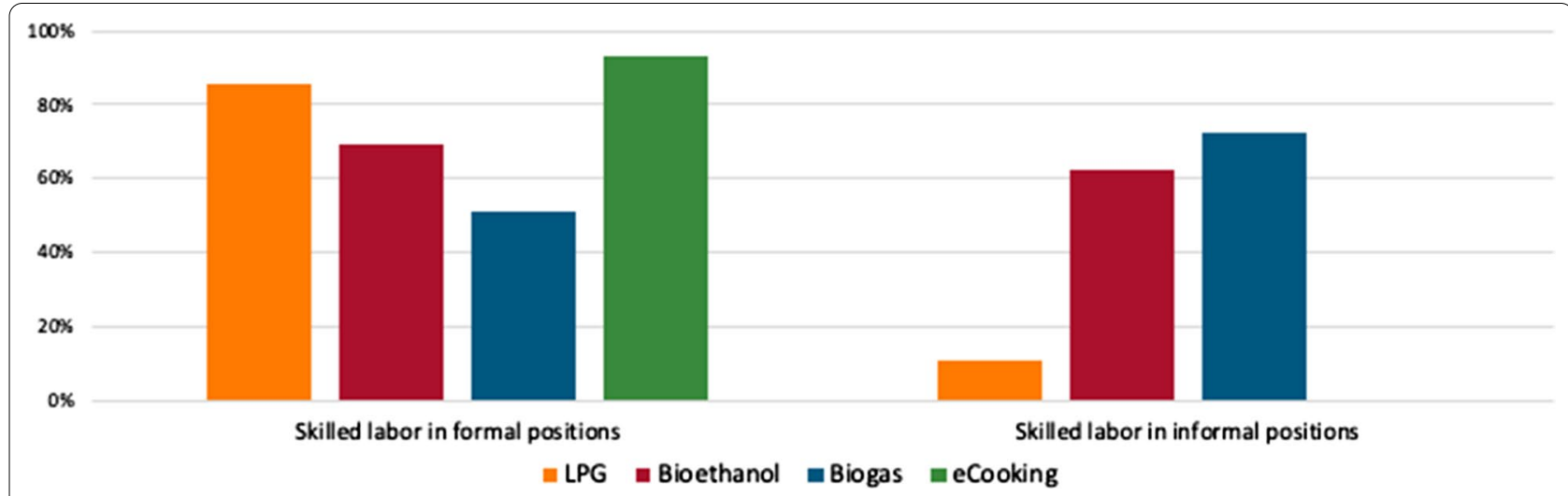

Fig. 10 Skill level of formal and informal workers across clean cooking technologies

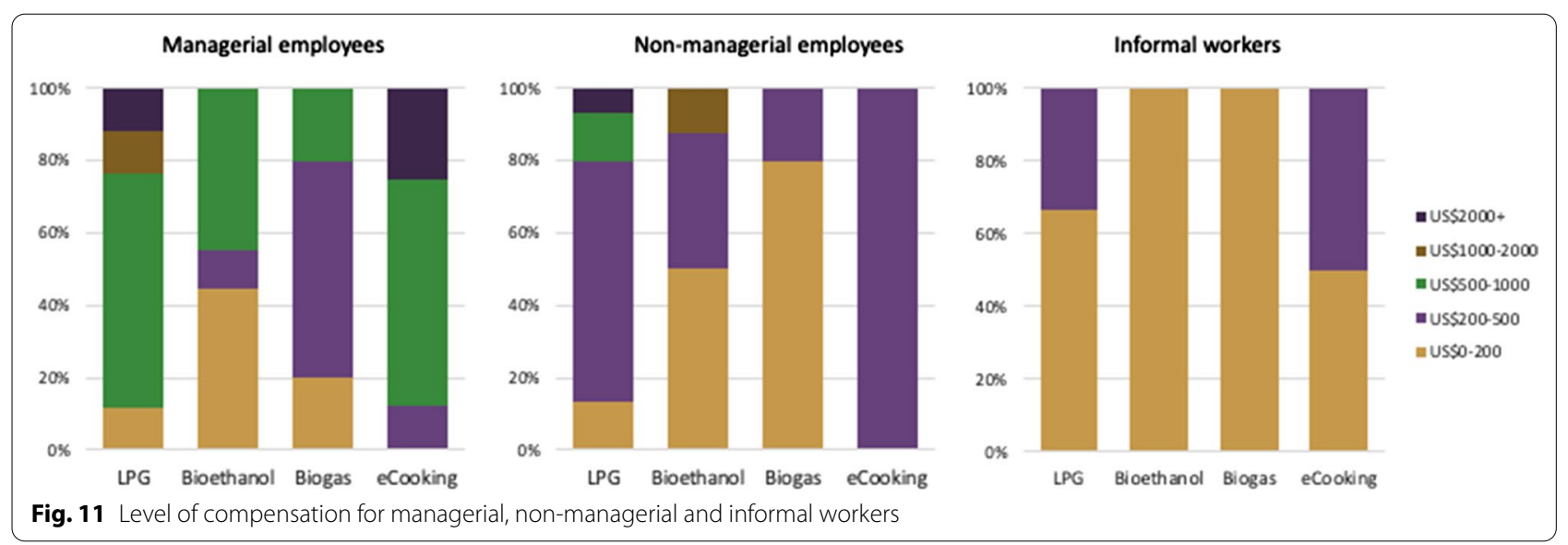




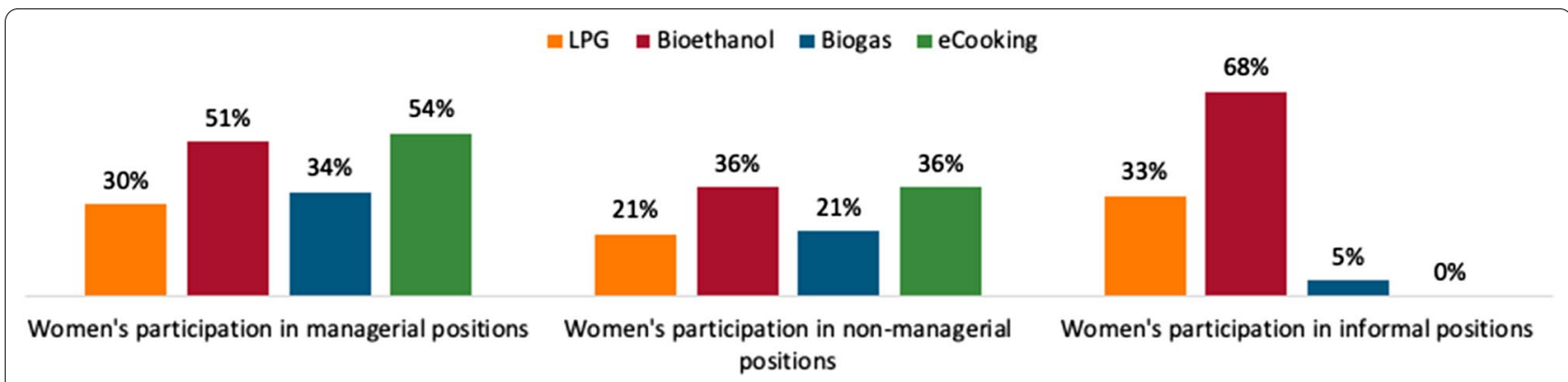

Fig. 12 Women's participation in managerial, non-managerial and informal positions

jobs are the construction and installation work that more men than women are willing to perform. This also explains the low women's participation in informal jobs. According to participants in the focus group discussion, other barriers for women to work in the clean cooking sector include perceived limitations to travel, the perception of danger associated with and distribution of fuel, and the stigma associated with the sector. Particularly in the bioethanol sector, there is a negative connotation with "drinking alcohol" which therefore sometimes deters talents.

On the other hand, women are highly valued in some key positions such as analytics, finances, marketing, sales, customer relations, and business administration. In Kenya, almost $100 \%$ of the end-use consumers of cooking fuel and technologies are women. Therefore, sales activities are often performed better by women than men [26].

Women's participation is also highly valued in product research and design. Companies and focus group discussion participants expressed strong interest in engaging women in these activities, particularly because women are more aware of the needs of the end users, who are also mostly women.

According to the focus group discussion participants, the changing market dynamics of the clean cooking sectors may provide an opportunity for better women's engagement. In parts of the LPG value chain, such as cylinder manufacturing, revalidation, and filling, the process is highly automated. The automation trend may see a shift of workforce need from hard labor to machine operation and management, and therefore, provide more opportunity for women. In the biogas sector, the technology shift from fixed-dome digesters to the moveable systems may also provide an opportunity for women, since the deployment of these moveable systems require less construction labor, which is traditionally held by more men than women.

While the study scope does not capture productive use jobs through income-generating activities by the endusers, literature has shown strong links between gender empowerment and clean cooking. Fuel-switching to cleaner and more efficient cooking methods free up time for households $[7,11]$.

The survey data show that youth participation in the clean cooking sectors studied is high (Fig. 13). The LPG sector has lower youth participation in its formal workforce than informal. Higher youth participation in the informal workforce may be associated with lower skill requirements. Focus group experts also commented that LPG companies are interested in working with and often train youth groups to sell and distribute their products. Bioethanol companies express strong interest in hiring young people, and they often train young people into senior positions. In the biogas sector, while there is a high youth participation, young people may face capital

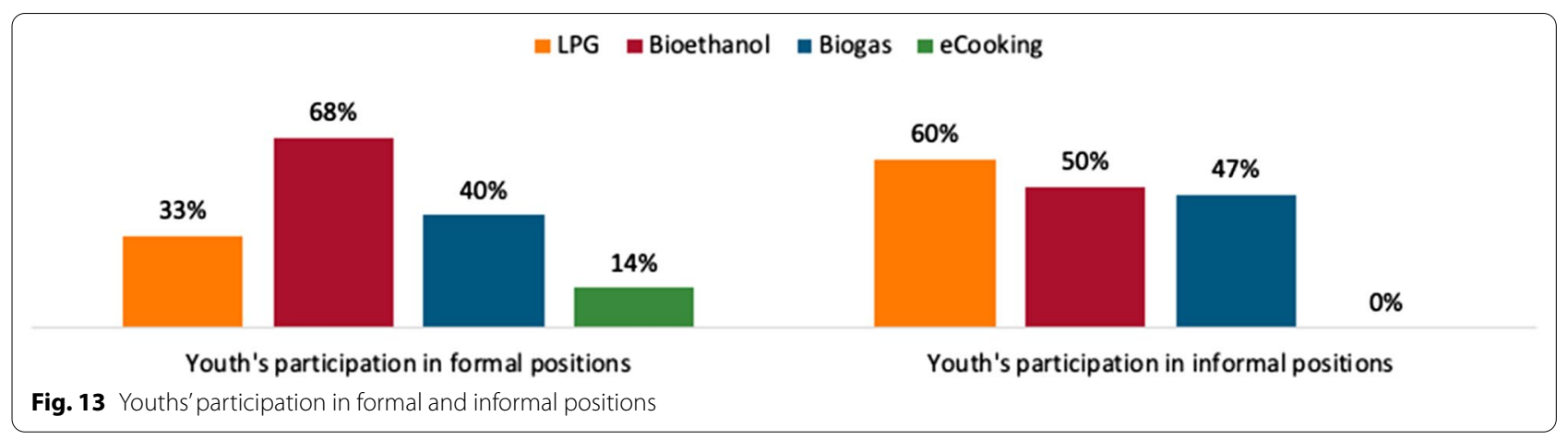


constraints and find it difficult to start their own businesses after training as biogas constructors or installers.

\section{Recruitment challenges and skill development needs}

According to the survey data the LPG sector has a wide and diverse job function breakdown, as seen in Fig. 14. The skills are evenly spread across different job functions, with slightly more demand for sales and marketing, and after-sales service talents. The bioethanol and biogas sector, on the other hand, has a stronger need for manufacturing and assembly workforce. The electric cooking sector has a large share of its workforce in sales and distribution.

A job function breakdown for the clean cooking sectors paired with insight into recruitment difficulty by job function provides an indication to where the skill demand and skill gaps exist. While most companies have a strong need for sales and after-sales service workforce, not many find these talents difficult to recruit, as shown in Fig. 15.

On the other hand, senior management, finance and legal persons are reported as the most difficult to recruit. According to participants in the focus group discussion this is likely because the rapidly changing regulatory environment in the clean cooking sector makes it more difficult to find willing legal professionals. Companies also express more interest in recruiting entry-level talents and training them into managerial positions, rather than recruiting for managerial talents externally. This is particularly pronounced in the bioethanol sector. In the biogas sector, companies have strong preference in recruiting technical talents for their "core functions" and outsourcing finance or business administration. Research and development represent another skill gap in the biogas sector. According to participants in the focus group discussion, research and development talents are costly and difficult to find.

While the clean cooking sector creates many jobs for young talents and is investing resources in training entrylevel professionals into managerial positions, experts expressed concerns for the mismatch between formal education and the technical skills required in the sector day-to-day. In particular, graduates often lack soft skills and workplace readiness, according to the focus group discussion.

\section{Discussion}

Practical implications of the data findings

In 2019 the Kenyan clean cooking sectors employed roughly $11,000-19,000$ persons and potentially more
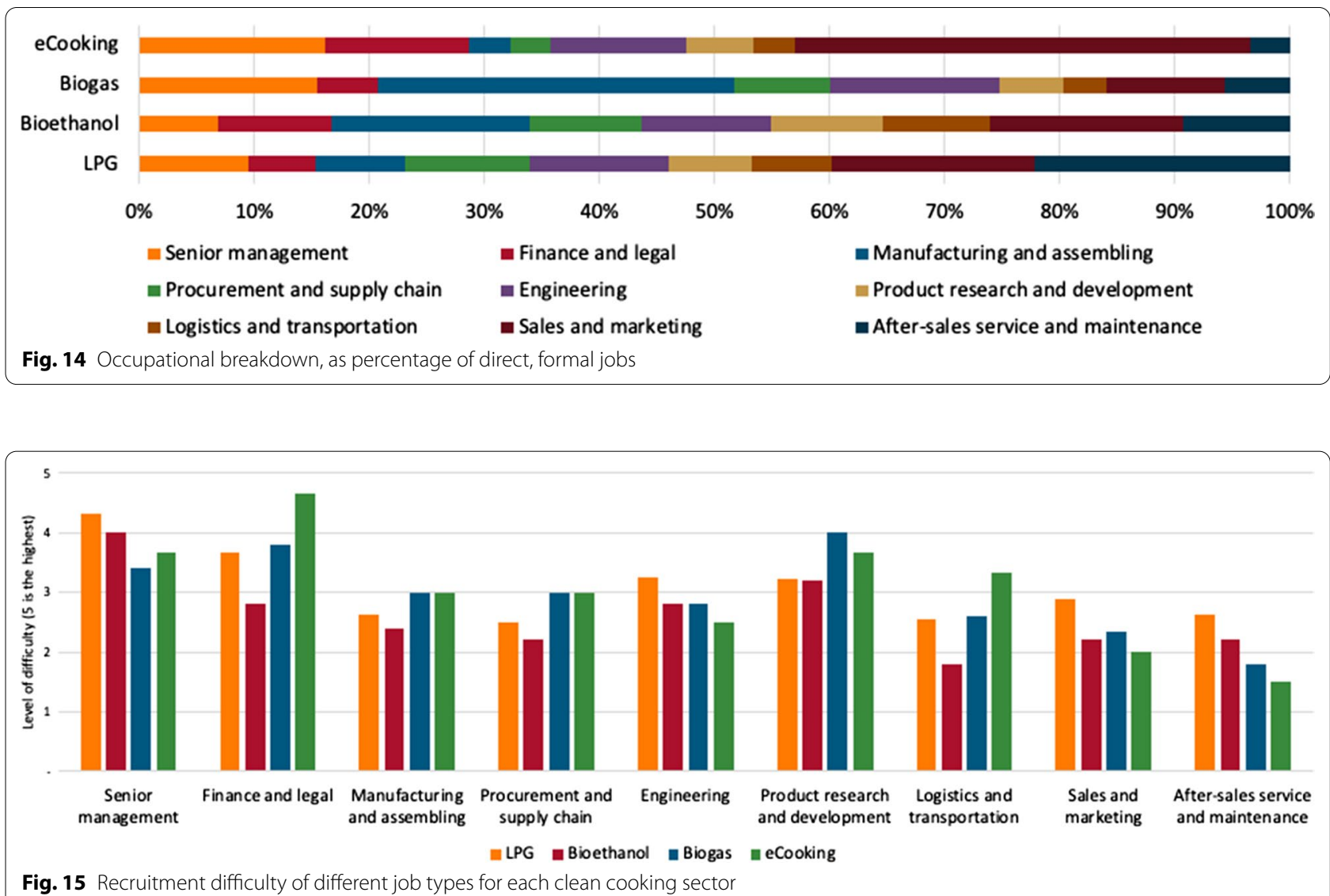

Fig. 15 Recruitment difficulty of different job types for each clean cooking secto 
than 35,000 through direct informal engagement, mainly through downstream linkages with the retail businesses. While the LPG sector has a high informal employment footprint, this is expected to change as the Kenyan government continues to formalize the downstream value chain after the introduction of $\mathrm{LN} 100 / 2019$. While the new regulations have a positive impact on ensuring the health and safety of LPG workers, this process may have a short-term negative impact on some of the smaller retail businesses that do not have the capital or the ability to become licensed. The government can mitigate this by continuous policy communication and small business support.

While the clean cooking sectors studied employ many persons, the data finds that levels of compensation are low, especially compared to that of the decentralized renewable energy sectors [25]. Average compensation is barely in the range of Kenya's middle income bracket of US $\$ 10$ to 20 per day [4]. In comparison, charcoal workers earn about US\$ 60 per month (or US $\$ 2$ per day, just above the Kenya poverty line of US\$1.9 per day of 2011 PPP), workers in clean cooking sectors earn more, though still low.

However, there is no clear evidence that charcoal workers can easily transition themselves into the clean cooking sectors. Despite Kenya's commitment to full access to clean cooking by 2030, there is no clear policy pathway to re-skill the traditional biomass workforce. Considering the potential high job displacement effect this transition might have on the charcoal sector, mitigation measures should be considered.

As of 2019, LPG is the single most important jobs engine in the clean cooking sector. Bioethanol and biogas are emerging as key drivers, particularly for rural employment. Bioethanol has a wide impact on sugarcane farmers, while biogas creates productive use opportunities through a diverse range of applications. To reap the employment benefits of productive uses of biogas systems, a stronger product development, research and innovation workforce is needed.

While product research and development skills represent one of the biggest gaps in the clean cooking workforce, it also provides a direct opportunity for strengthening women's participation in the formal workforce, which is currently lower than $30 \%$ on average. Companies express high interest in engaging women in product design and innovation, especially because most of their users are women.

Several sectoral trends also shed light on opportunities for women. In the biogas sector, a shift towards moveable technologies is changing the perception of the biogas jobs from what used to be perceived as labor-intensive masonry to jobs that require sales and marketing skills. In addition, there is also a major opportunity in tapping into the referral network capabilities of women end-users.

The majority of the direct, formal workforce is reported to be skilled, with a wider potential for semi-skilled and unskilled workers in the informal and indirect jobs. Skill development pathways are most often internal, and therefore, there is a strong need for workforce-ready entry-level talents. Formal institutions can help with preparing more workforce-ready young graduates.

Support for entrepreneurs is also reported to be lacking. In Kenya, recent estimates suggest that $46 \%$ of micro, small and medium enterprises (MSME) close down in their first year of operation [27]. Entrepreneurs face fierce competition among themselves. As the clean cooking sectors are highly dependent on MSMEs as their selling points, it is key to support the sustainable operation of these small businesses.

For the biogas sector, almost $60 \%$ of the market share is served by entrepreneurs. Currently, the government's tax exemption benefits only large shipments of prefabricated systems and these benefits are not captured by the small entrepreneurs [15]. For the sector to grow, clear guidelines for entrepreneurs to obtain tax exemption status is needed.

\section{Study limitations \\ Impact of new access}

The data here provide employment estimates for the clean cooking sectors, but does not represent jobs from "new access" only. It is difficult for companies to specifically identify those customers who are first time users of clean cooking technologies, and whether there is fuel stacking with other technologies in the home. In the survey, companies were asked to estimate the likelihood of fuel stacking, but the additionality of new clean cooking users and its job creation impact can be better captured through follow-up surveys.

\section{Consideration of jobs displacement}

The employment impact of the clean cooking sector has a strong element of job displacement caused by fuelswitch. The World Bank estimates that the sub-Saharan Africa charcoal sector alone employs 7 million persons in Africa, with aggregate employment expected to reach 12 million by 2030 [11]. Recent individual country studies estimate the involvement of 700,000 people in the charcoal sector in Kenya [11]. Given the lack of available data, the study does not explore job displacement. This is a major limitation towards understanding the scale of net employment. Broader macro-economic studies are required. 


\section{Sample period}

The data represents only one year of employment history. Trends are likely to change in the future and thus further surveying would allow for a more nuanced understanding of employment scale, and future predictions. The study addressed this limitation through focus group discussion that help provides insights into future trends.

\section{Sample representation}

Further, the sample size is limited and may not capture certain value chain segment areas. For instance, the survey only covers EPC as electric cooking technologies, while there are many other electrical appliances for cooking such as, water boilers and toasters that are available in Kenya. Furthermore, the sample may not capture the value chain of every hardware and/or equipment used in LPG production, including LPG valves, regulators, and other equipment manufacturing. It also does not take into consideration the deployment and maintenance of bioethanol fuel dispensing technologies. Thus, future studies should incorporate these elements for the job estimates to be more comprehensive.

\section{High-quality market estimate data}

The study applies employment factors to best-available market estimates for Kenya. However, there exists very little market data on bioethanol fuel consumption and EPC sales, which reduces confidence in the estimates produced. Most recent and best-available estimates are used where possible but stronger market data are needed for the sector. Through interviews with sector experts and focus group discussions, we were able to validate some market estimates.

\section{Comparability of direct formal and informal jobs}

Direct informal jobs cannot be fully estimated. Due to lack of data about the nature and time involved in work, direct informal and productive use jobs are not translated into FTE terms and therefore cannot be readily compared in scale to direct formal jobs. Furthermore, the study does not yet explore the status of the informal retail businesses that support the sales and distribution of LPG and bioethanol fuel. Consequently, the numbers reported in this study are not comparable with the direct formal jobs. We mitigated this limitation by engaging with EPRA, who is in the process of licensing all LPG retail businesses. Future studies should work closely with the government to encourage continuous and transparent reporting and tracking of jobs in the LPG retail businesses.

\section{Productive use jobs}

The study only briefly discussed the productive use jobs in the biogas sector. There is a wider cost-saving and income generation opportunity from the productive use of clean cooking fuel and technologies for heating, milling, drying, pasteurization, etc. These activities are not part of the scope of our survey tool, and require end-user facing studies to quantify.

\section{Conclusions}

This study has provided a comprehensive overview of employment in Kenya's clean cooking sectors. We find that in 2019, the clean cooking sectors, including LPG, bioethanol, biogas, and electric cooking, employed about 11,00019,000 persons through direct formal engagement and potentially 35,000 persons through direct informal engagement. According to the latest estimate by the Ministry of Energy, Kenya, most of the jobs are now in the LPG sector, which currently supplies $29.7 \%$ of households [2]. The bioethanol sector may create additional value in its upstream raw material production activities for the sugarcane farmers [13]. Further, in the downstream linkages, the biogas sector has high potential to provide productive use jobs.

The skill level of the direct formal jobs in the clean cooking sectors is high across the board. The most indemand skills are sales and distribution in the LPG and electric cooking sectors while in bioethanol and biogas sectors, manufacturing and assembly are the most common job functions. Product research and development skills are reported to be the most difficult to recruit.

Women's participation in the sector is low, especially in the LPG and biogas sector, where only about one-fifth of the non-managerial workforce are women due to the laborintensive activities involved in these jobs. In managerial positions, the clean cooking sectors see higher women's participation. Women represent about one-third of the managers in the LPG and biogas sectors and half in the bioethanol and electric cooking sectors. Companies generally express strong interest in engaging women in managerial positions and product research and development. These are also the positions that are reported to be the most difficult to fill. The clean cooking sectors are thus presented with a unique opportunity to close the skill gap and gender gap.

This research exercise establishes a baseline for understanding the employment trends and impact of the clean cooking sectors. However, a massive data gap still persists. Our study shows that while the clean cooking sectors, especially LPG, are already providing tens of thousands of jobs, further studies are critically needed to map the employment impact of delivering universal clean cooking access and to understand displacement.

Kenya's Sustainable Energy for All Action Agenda commits to achieving universal clean cooking access by 2030 . Many trends will determine the size and characteristics of clean cooking workforce, including the shift away from biomass-based solutions to modern energy, formalization 
of the fuel retail businesses, growing market share of prefabricated biogas digester providers, entrants of global conglomerates into the bioethanol sector, among others. Success in leveraging these trends to support the clean cooking sectors can accelerate Kenya's clean energy transition while providing jobs to tens of thousands workers.

This study is the first attempt towards understanding the current clean cooking employment trends in a systematic and structured way. Future iteration will provide more insights on job growth predictions and future workforce trends.

\section{Appendix 1}

Employment factor An employment factor measures the number of jobs per unit of produced product or service. For instance, direct employment factors are calculated based on the number of total direct, formal jobs and number of products sold or systems built, in sales unit or capacity terms.

Full-time employment A full-time employee is on the payroll with a registered company, enjoys benefits as an employee, and works full-time hours, which is generally more than $35 \mathrm{~h}$ per week, but this may differ according to company policy.

Part-time employment A part-time employee is on the payroll with a registered company but does not work fulltime hours, which is defined according to company policy.

FTE job An FTE job is the equivalent of one employee working full time over the course of a year where full-time work is defined in accordance with the country context. Part-time and contract work are converted to FTE based on the number of hours worked or length of contract. All estimates of direct formal jobs are presented in FTE job terms. All other references to jobs outside of direct formal employment do not assume full-time equivalency.

Direct formal jobs In the scope of this study, direct formal jobs are those created through contractual engagement with an incorporated company in the clean cooking sector. For example, an IT professional or a project manager who is employed by a clean cooking company.

Indirect jobs Indirect jobs are those created by backward-linked industries or companies that serve and supply the clean cooking sector. That is, those vendors and suppliers who serve the sector upstream or provide services for the sector's day-to-day operations either contractually or non-contractually. For example, indirect employment can be observed in sugarcane farming activities that supply the raw material for bioethanol.

Informal sector According to the ILO, the informal sector comprises all work for unincorporated enterprises and for which no complete accounts are available that would permit a financial separation of the production activities of the enterprise from other activities of its owner(s). Informal jobs can even be extended to include non-remunerative work of contributing family members, and thus can be difficult to bound definitively [28].

Direct informal jobs Those informal jobs that are created through contractual or non-contractual engagement with an incorporated company in the clean cooking sector. Informal employment in the sector takes on various forms-from long-term arrangements with companies (e.g., product retail) to commission-based sales activities. For example, a home business that works as a selling point for a bioethanol fuel.

Induced jobs Induced jobs are those created through forward linkages as workers in the clean cooking sector spend salaries on goods and services throughout the larger economy. For example, during the construction of a biogas plant, induced jobs are created for masons at the construction site. Induced jobs are estimated using "job multipliers". However, this study does not explore the macro-economic effects of spending on the economy and further job creation thereof. Induced jobs are excluded from the analysis and this report.

Productive use jobs Productive use jobs are those created by the end users themselves as a result of newly acquired or enhanced electricity access. For the purpose of this study, productive use is defined as any income-generating application of a clean cooking product or service [29].

Retention Retention is the total period of time that an employee continues to work with an organization.

Senior managers For the purpose of this study, senior managers include the top executive management of a company, such as the CEO, CFO, and COO.

Skilled workers Skilled workers are those who hold leadership, management, professional, technical, or associate professional positions. Their responsibilities typically involve the performance of complex technical and practical tasks that require an extensive body of factual, technical, and procedural knowledge in a specialized field, as defined by the International Standard Classification of Occupation (ISCO-08) Skill Level [30]. Workers in Skill Level 3 or above are considered skilled workers. While there is a qualification and skills framework developed by the East African Community, there is little substantial difference between these frameworks [31]. Our study adopts the ILO framework to allow for consistency and comparability with results from other SSA countries.

Youth Youth are defined as persons between the ages of 15 to 24 .

\section{Appendix 2}

\section{Employment factors and jobs estimates}

Tables 2, 3, 4, 5 summarize the employment factors used by the study to scale the job numbers. All reported job numbers are rounded to two significant figures. 
Table 2 Employment factors and jobs estimates of the LPG sector

\begin{tabular}{|c|c|c|c|c|}
\hline LPG value chain activities & Direct formal employment factor & Direct informal employment factor & $\begin{array}{l}\text { Direct formal } \\
\text { jobs estimate }\end{array}$ & $\begin{array}{l}\text { Direct informal } \\
\text { jobs estimate }\end{array}$ \\
\hline LPG import and wholesale & 0.015 jobs per tonne & 0.000 jobs per tonne & 3400 & 0 \\
\hline LPG transportation in bulk & 0.002 jobs per tonne & 0.001 jobs per tonne & 400 & 300 \\
\hline LPG storage and filling & 0.004 jobs per tonne & 0.000 jobs per tonne & 1000 & 0 \\
\hline LPG wholesale in cylinder & 0.013 jobs per tonne & 0.000 jobs per tonne & 3100 & 0 \\
\hline LPG retail sales in cylinders & 0.016 jobs per tonne & 0.000 jobs per tonne & 3800 & 0 \\
\hline LPG cylinders manufacturing & 0.260 jobs per 1000 cylinders & 0.000 jobs per 1000 cylinders & 520 & 0 \\
\hline LPG cylinder revalidation & 0.571 jobs per 1000 cylinders & 0.000 jobs per 1000 cylinders & 170 & 0 \\
\hline LPG stove manufacturing & 0.000 jobs per 1000 stoves & 0.000 jobs per 1000 stoves & 0 & 0 \\
\hline LPG stoves sales and distribution & 45 jobs per 1000 stoves & 0.059 jobs per 1000 stoves & 4500 & 10 \\
\hline
\end{tabular}

Table 3 Employment factors and jobs estimates of the bioethanol sector

\begin{tabular}{|c|c|c|c|c|}
\hline Bioethanol value chain activities & Direct formal employment factor & Direct informal employment factor & $\begin{array}{l}\text { Direct formal } \\
\text { jobs estimate }\end{array}$ & $\begin{array}{l}\text { Direct informal } \\
\text { jobs estimate }\end{array}$ \\
\hline Bioethanol production & 0.014 jobs per $1000 \mathrm{~L}$ & 0.000 jobs per $1000 \mathrm{~L}$ & 80 & 2 \\
\hline Bioethanol wholesale & 0.055 jobs per $1000 \mathrm{~L}$ & 0.000 jobs per $1000 \mathrm{~L}$ & 320 & 2 \\
\hline Bioethanol distribution & 0.003 jobs per $1000 \mathrm{~L}$ & 0.012 jobs per $1000 \mathrm{~L}$ & 20 & 70 \\
\hline Bioethanol end-user sales & 0.047 jobs per $1000 \mathrm{~L}$ & 0.130 jobs per $1000 \mathrm{~L}$ & 270 & 750 \\
\hline Bioethanol stove manufacturing & 0.258 jobs per 1000 stoves & 0.117 jobs per 1000 stoves & 4 & 2 \\
\hline $\begin{array}{l}\text { Bioethanol stove sales and distribu- } \\
\text { tion }\end{array}$ & 2.396 jobs per 1000 stoves & 2.604 jobs per 1000 stoves & 40 & 40 \\
\hline
\end{tabular}

Table 4 Employment factors and jobs estimates of the biogas sector

\begin{tabular}{|c|c|c|c|c|}
\hline Biogas value chain activities & Direct formal employment factor & Direct informal employment factor & $\begin{array}{l}\text { Direct formal } \\
\text { jobs estimate }\end{array}$ & $\begin{array}{l}\text { Direct informal } \\
\text { jobs estimate }\end{array}$ \\
\hline $\begin{array}{l}\text { Biogas digester importing and } \\
\text { assembly }\end{array}$ & 2 jobs per 1000 biogas digesters & 0 jobs per 1000 biogas digesters & 5 & 0 \\
\hline $\begin{array}{l}\text { Biogas digester manufacturing and } \\
\text { fabrication }\end{array}$ & 210 jobs per 1000 biogas digesters & 0 jobs per 1000 biogas digesters & 450 & 0 \\
\hline $\begin{array}{l}\text { Biogas digester installation and } \\
\text { construction }\end{array}$ & 30 jobs per 1000 biogas digesters & 9 jobs per 1000 biogas digesters & 220 & 770 \\
\hline Biogas digester after-sale service & 15 jobs per 1000 biogas digesters & 2 jobs per thousand biogas digesters & 320 & 50 \\
\hline $\begin{array}{l}\text { Biogas stoves manufacturing and } \\
\text { fabrication }\end{array}$ & 6 jobs per 1000 stoves & 0 jobs per 1000 stoves & 10 & 0 \\
\hline Biogas stoves sales and distribution & 7 jobs per 1000 stoves & 0 jobs per 1000 stoves & 20 & 0 \\
\hline
\end{tabular}

Table 5 Employment factors and jobs estimates of the eCooking sector

\begin{tabular}{lllrr}
\hline Electric cooking value chain activities & Direct formal employment factor & $\begin{array}{l}\text { Direct informal } \\
\text { employment factor }\end{array}$ & $\begin{array}{c}\text { Direct formal } \\
\text { jobs estimate }\end{array}$ & $\begin{array}{c}\text { Direct } \\
\text { informal jobs } \\
\text { estimate }\end{array}$ \\
\hline EPC manufacturing and assembly & 0 jobs per 1000 stoves & 0 jobs per 1000 stoves & 0 & 0 \\
EPC import and wholesale & 3 jobs per 1000 stoves & 0 jobs per 1000 stoves & 10 & 0 \\
EPC retail sales and distribution & 50 jobs per 1000 stoves & 9 jobs per 1000 stoves & 210 & 770 \\
\hline
\end{tabular}




\section{Abbreviations}

AGOL: African Gas \& Oil Limited; BCE: Biogas Construction Entrepreneurs; EPC: Electric pressure cooker; EPRA: Energy and Petroleum Regulatory Agency; EDA: Energy Dealers Association; FTE: Full-time equivalence; GLPGP: Global LPG Partnership; ILO: International Labour Organization; KBP: Kenya Biogas Program; LPG: Liquefied petroleum gas; MSME: Micro, small and medium enterprises; M\&E: Monitoring and evaluation; O\&M: Operations and maintenance; R\&D: Research and development.

\section{Supplementary Information}

The online version contains supplementary material available at https://doi. org/10.1186/s13705-021-00299-0.

Additional file 1. Clean cooking jobs survey tool.

\section{Acknowledgements}

The authors wish to thank Donna Gaya, Research Analyst at Power for All, for editing support and constructive comments on paper style. The authors also wish to thank all survey respondents and interview participants for their data input, and all colleagues from NGOs, clean cooking companies, and research institutions that reviewed the work and provided feedback.

\section{Authors' contributions}

$\mathrm{CL}$ and $\mathrm{RS}$ conceptualized the study and developed its methodology. CL, MO and $\mathrm{HN}$ curated the sample and collected the data. CL conducted the formal analysis and visualized the data findings. CL and RS prepared the original draft, reviewed and edited the manuscript. RS supervised and administered the study. All authors have read and agreed to the published version of the manuscript.

\section{Funding}

This research was kindly funded by Modern Energy Cooking Services (MECS), a five-year programme funded by UK Aid (FCDO). Funding was acquired by Power for All.

\section{Availability of data and materials}

All data generated or analyzed during this study are included in this published article and the Appendices 1, 2.

\section{Declarations}

\section{Ethics approval and consent to participate}

Not applicable. This manuscript does not report on or involve the use of any animal or human data or tissue.

\section{Consent for publication}

Not applicable. This manuscript does not contain any individual person's data in any form.

\section{Competing interests}

The authors declare no conflict of interest. The funders had no role in the design of the study; in the collection, analyses, or interpretation of data; in the writing of the manuscript, or in the decision to publish the results.

\section{Author details}

${ }^{1}$ Power for All, San Francisco, CA 94108, USA. ${ }^{2}$ Strathmore Energy Research Center, Strathmore University, Nairobi 00200, Kenya.

Received: 31 July 2020 Accepted: 30 June 2021

Published online: 13 August 2021

\section{References}

1. (2019) Tracking SDG 7: The Energy Progress Report. IEA, IRENA, UNSD, WB, WHO, Washington DC
2. (2019) Kenya Household Cooking Sector Study: Assessment of the Supply and Demand of Cooking Solutions at the Household Level. Kenya Ministry of Energy. https://eedadvisory.com/wp-content/uploads/2020/ 09/MoE-2019-Kenya-Cooking-Sector-Study-compressed.pdf. Accessed 30 Jul 2021

3. Ekkehard K, Diehl E, Hermann-Friede J, Hornikel C, Rosenbusch J, Sagmeister E (2009) Impacts of basic rural energy services in Bangladesh: an assessment of solar home system and improved cook stove interventions

4. Wanjiru H, Nyambane A, Omedo G, Davis M, Chelagat W (2016) How Kenya can transform the charcoal sector and create new opportunities for low-carbon rural development. Stockholm Environment Institute

5. World Bank Data. https://data.worldbank.org/indicator/SP.RUR.TOTL.ZS. Accessed 17 Mar 2020

6. Poor people's energy outlook (2016) National energy planning from the bottom up. Practical Action Publishing, Rugby

7. Dutta S (2018) Supporting last-mile women energy entrepreneurs: What works and what does not. ENERGIA

8. (2019) Powering Jobs 2019: Energy Access Jobs Census. Power for All. https://www.powerforall.org/resources/reports/powering-jobs-census2019-energy-access-workforce. Accessed 30 Jul 2021

9. (2012) Renewable Energy Jobs and Access. IRENA. https://www.irena.org/ publications/2012/Jun/Renewable-Energy-Jobs--Access-2012. Accessed 30 Jul 2021

10. (2016) Le Cameroun adopte son premier Plan Directeur National GPL élaboré avec The Global LPG Partnership, visant à permettre le développementdu Gaz GPL domestique. Global LPG Partnership. Press release. https://static1.squarespace.com/static/5633c4c2e4b05a5c7831fbb5/t/ 5a9ec57fe4966bb23fdb5ce3/1520354691201/Press+Release+-+Camer oon+LPG+Master+Plan+\%28fr\%2C+en\%29+14+Dec+2016.pdf. Accessed 30 Jul 2021

11. Putti VR, Tsan M, Mehta S, Kammila S (2015) The state of the global clean and improved cooking sector. World Bank Group

12. Asu F (2017) LPG market can create two million jobs - NLPGA. In: Punch Newspapers. https://punchng.com/lpg-market-can-create-two-millionjobs-nlpga/. Accessed 17 Mar 2020

13. (2018) Scaling up clean cooking in urban Kenya with LPG \& Bioethanol. Dalberg. https://dalberg.com/our-ideas/cleaning-cooking-urban-kenyalpg-and-bio-ethanol/. Accessed 30 Jul 2021

14. (2017) Biogas for domestic cooking: technology brief. IRENA. https:// www.irena.org/publications/2017/Dec/Biogas-for-domestic-cookingTechnology-brief. Accessed 30 Jul 2021

15. Clemens H, Bailis R, Nyambane A, Ndung'u V (2018) Africa Biogas Partnership Program: a review of clean cooking implementation through market development in East Africa. Energy Sustain Dev 46:23-31. https://doi.org/ 10.1016/j.esd.2018.05.012

16. (2019) National Feasibility Study: LPG for Clean Cooking in Kenya. Global LPG Partnership, New York

17. (2019) The Petroleum Act, No. 2 of 2019. The Republic of Kenya. http:// kenyalaw.org/kl/fileadmin/pdfdownloads/Acts/2019/PetroleumAct_No._ 2of2019.pdf. Accessed 30 Jul 2021

18. Kamau M (2020) Cooking gas dealers upstage multinationals in market share. In: The Standard. https://www.standardmedia.co.ke/article/20013 56434/cooking-gas-dealers-upstage-multinationals-in-market-share. Accessed 17 Mar 2020

19. Kammen DM, Kapadia K, Fripp M (2008) Putting renewables to work: how many jobs can the clean energy industry generate? 28

20. Wei M, Patadia S, Kammen DM (2010) Putting renewables and energy efficiency to work: how many jobs can the clean energy industry generate in the US? Energy Policy 38:919-931. https://doi.org/10.1016/j.enpol. 2009.10.044

21. LeontiefW (Ed.) (1986) Input-output economics. Oxford University Press.

22. A handbook on a methodology for estimating green jobs in bioenergy. International Labour Organization, Buenos Aires (2020).

23. Petroleum Registers. In: Energy and Petroleum Regulatory Authority. https://www.epra.go.ke/services/petroleum/petroleum-licence-register/. Accessed 19 May 2020

24. Ndegwa G, Moraa $V$, liyama M (2011) Potential for biofuel feedstock in Kenya. World Agroforestry Centre (ICRAF)

25. Shirley R, Lee C-J, Njoroge HN, Odera S, Mwanzia PK, Malo I, Dipo-Salami $Y$ (2019) Powering jobs: the employment footprint of decentralized 
renewable energy technologies in sub saharan Africa. J Sustain Res. https://doi.org/10.20900/jsr20200001

26. Solar Sister: empowering women through clean energy entrepreneurship. ICRW (2015)

27. Omondi D (2016) Why 400,000 SMEs are dying annually. In: The Standard. https://www.standardmedia.co.ke/business/article/2000221491/why400-000-smes-are-dying-annually. Accessed 17 Mar 2020

28. Hussmanns R (2003) Statistical definition of informal employment: Guidelines endorsed by the Seventeenth International Conference of Labour Statisticians. International Labour Office, Bureau of Statistics, New Delhi

29. Mayer-Tasch L, Mukherjee M, Reiche K (2013) Productive Use of Energy - PROUSE: Measuring Impacts of Electrification on Small and Micro-Enterprises in Sub-Saharan Africa. GIZ
30. International Standard Classification of Occupations (2012) Structure, group definitions and correspondence tables. International Labour Organization, Geneva

31. East African Qualifications Framework for Higher Education. East African Community (2014)

\section{Publisher's Note}

Springer Nature remains neutral with regard to jurisdictional claims in published maps and institutional affiliations.
Ready to submit your research? Choose BMC and benefit from:

- fast, convenient online submission

- thorough peer review by experienced researchers in your field

- rapid publication on acceptance

- support for research data, including large and complex data types

- gold Open Access which fosters wider collaboration and increased citations

- maximum visibility for your research: over $100 \mathrm{M}$ website views per year

At BMC, research is always in progress.

Learn more biomedcentral.com/submissions 